\title{
Currículo de história e agência docente: possibilidades de articulação nos anos iniciais do ensino fundamental ${ }^{1}$
}

\author{
History curriculum and teaching agency: possibilities of articulation \\ in the early years of fundamental education
}

\section{Currículo de historia y agencia docente: posibilidades de articulación en los años iniciales de enseñanza primaria}

\section{Carmen Teresa Gabriel ${ }^{2}$}

Universidade Federal do Rio de Janeiro, Professor titular. https://orcid.org/0000-0001-9503-6740

\section{Tatiana Polliana Pinto de Lima}

Universidade Federal do Recôncavo da Bahia, Programa de Pós-graduação em Currículo, Linguagens e Inovações Pedagógicas e Programa de Pós Graduação em Educação Científica, Professora adjunta.

https://orcid.org/0000-0003-2896-5616

Resumo: Este texto tem por objetivo explorar as articulações entre a produção de currículos de História e os processos de subjetivação política mobilizados pelas professoras dos Anos Iniciais do Ensino Fundamental, na relação estabelecida com o conhecimento histórico legitimado como objeto de ensino. As contribuições das teorizações curriculares pós-estruturalistas e da pesquisa biográfica ofereceram o quadro de inteligibilidade no âmbito do qual significamos e operamos, nesta escrita, com as categorias analíticas selecionadas. Nesse movimento procuramos compreender a relação estabelecida pelas docentes com o saber histórico escolar. Na perspectiva aqui privilegiada, o entendimento da natureza dessa relação é uma chave de leitura incontornável para a compreensão da articulação pretendida. Ao longo do texto, buscamos sustentar e argumentar a favor da potência heurística de trabalharmos na interface de duas hipóteses: (i) os/as docentes produzem e reinventam currículos no seu cotidiano profissional por meio do tipo de relação estabelecida com

\footnotetext{
A produção desse texto está diretamente vinculada aos estudos desenvolvidos no âmbito de dois projetos de pesquisa em curso: Currículo como espaço biográfico: Subjetivação e profissionalização docente em múltiplos tempos e espaços (CNPqBolsa de Produtividade) e Currículo como espaço biográfico: conhecimento, sujeitos e demandas em diferentes percursos formativos (CNE/FAPERJ).

2 Pós-doutora pela Université des Sicences Humaines de Lille 3; Doutora em Educação pela Pontificia Universidade Católica do Rio de Janeiro.

3 Doutora e Mestre em Educação pela Universidade Federal da Bahia;
} 
o conhecimento na sala de aula e (ii) a agência docente está diretamente vinculada à maneira de como elas significam essa relação. Selecionamos como campo empírico um conjunto de narrativas de docentes dos Anos Iniciais cujas práticas profissionais exercidas em culturas escolares distintas têm em comum o fato de serem reconhecidas, pelos seus próprios pares, como diferenciadas e instigantes no que diz respeito ao ensino de História nesse nível de ensino.

Palavras-chave: Currículo de história. Relação com o saber. Agência. Ensino fundamental.

Abstract: This text aims to explore the articulations between the production of History curricula and the processes of political subjectivation mobilized by the teachers of the Early Years, of Elementary Education, in the relation established with the legitimate historical knowledge as a teaching object. Contributions from post-structuralistic curricular theorizations and biographical research offered the framework of intelligibility within which we mean and operate, in this writing, with the selected analytical categories. In this movement, we seek to understand the relation established by teachers with school history knowledge. Here in the privileged perspective, understanding the nature of this relation is an essential reading key for understanding the intended articulation. Throughout the text we seek to support and argue in favor of the potential to work on the interface of two hypotheses: (i) the teachers produce and reinvent curricula in their professional daily life through the type of relation established with knowledge in the classroom and (ii) the teaching agency is directly linked to the way they signify this relation. We selected as an empirical field a set of Early Years teachers' narratives from whose professional practices in different school cultures have in common the fact that they are recognized, by their own peers, as differentiated and instigating regard to History teaching at this level of education.

Keywords: History curriculum. Relation with knowledge. Agency. Elementary education.

Resumen: Este texto tiene por objetivo explorar las articulaciones entre la producción de currículos de Historia y los procesos de subjetivación política movilizados por las maestras de los Años Iniciales de Enseñanza Primaria, en la relación establecida con el conocimiento histórico legitimado como objetivo de enseñanza. Las contribuciones de las teorizaciones curriculares posestructuralistas y de la investigación biográfica ofrecieron el cuadro de inteligibilidad en el ámbito del cual significamos y operamos, en esta escritura, con las categorías analiticas seleccionadas. En ese movimiento, tratamos de entender la relación establecida por las docentes con el saber histórico escolar. En la perspectiva aquí privilegiada, el entendimiento de la naturaleza de esa relación es una clave de lectura ineludible para la comprensión de la articulación pretendida. A lo largo del texto, buscamos sustentar y argumentar a favor de la potencia heurística de trabajar en la interfaz de dos hipótesis: (i) los/las docentes producen y reinventan currículos en su cotidiano profesional a través del tipo de relación establecida con el conocimiento en aula y (ii) la agencia docente está directamente vinculada al modo según el cual ellas significan esa relación. Seleccionamos como campo empírico un conjunto de narrativas de docentes de los Años Iniciales, cuyas prácticas profesionales, ejercidas en culturas 
escolares distintas, tienen en común el hecho de ser reconocidas, por sus propios pares, como diferenciadas y estimulantes, en lo que respecta a la enseñanza de Historia en ese nivel de enseñanza.

Palabras clave: Currículo de historia. Relación con el saber. Agencia. Enseñanza básica.

Recebido em 4 de março de 2020

Aceito em 3 de julho de 2020

Publicado em 24 de setembro de 2020

\section{PRIMEIROS DIÁLOGOS: DESAFIOS E APOSTAS DO RECORTE PRIUILEGIADO}

A conjuntura político-educacional de nosso presente não é das mais auspiciosas para quem defende projetos de escola e de sociedade 'justos' e 'democráticos'. Compreendendo que esses adjetivos não se definem per si, sendo seus sentidos fixados em meio às disputas entre diferentes grupos de interesse, este texto se inscreve no conjunto de estudos que apostam na importância de mantermos no horizonte de expectativa de nosso presente, a ideia, bastante ampla mas, não por isso, menos potente, de 'justiça social' como algo a ser permanentemente perseguido. Se essas afirmações são dificilmente contestadas nos debates acadêmicos da área, a maneira de lidar com elas, no entanto, assume múltiplas facetas que traduzem entendimentos plurais e distintos sobre, 'democracia', 'ação política' e 'resistência' em contextos discursivos específicos.

Reconhecer e investir teoricamente em possibilidades de articulação entre currículo de História e ação docente nas escolas da Educação Básica, tal como sugere o título atribuído a este texto, pode ser entendido, pois, como um caminho possível para a reflexão sobre essa busca incessante, anteriormente mencionada. Trata-se de exercitar de forma articulada, tal como proposto por Gramsci (1975), 'o pessimismo da inteligência' e o 'otimismo da vontade política', evitando, assim, caminhos teórico-metodológicos que ora imobilizam qualquer tentativa para pensar um novo cenário educacional, ao investirem, muitas vezes, em leituras saudosistas de um "passado que não volta mais", ora encarnam a ilusão pedagógica pela qual é possível prescrever formulações salvacionistas capazes de superar todos e quaisquer obstáculos.

Em tempos de reformas curriculares envolvendo tanto a Educação Básica quanto o Ensino Superior, em particular os cursos de licenciatura, gestadas em meio ao desmonte da "coisa pública", de ataques de grupos de interesses ultraliberais, bem como do recrudescimento do conservadorismo de ultradireita, exercitar essa articulação remete às 
críticas contundentes e recorrentes - formuladas por pesquisadores da área educacional, em particular do campo do Currículo (MACED0, 2015, 2017, 2018, 2019; CUNHA; LOPES, 2017; GABRIEL, 2015) - ao fetichismo em torno da produção e socialização de uma Base Nacional Comum Curricular (BNCC), apresentada pelos seus defensores como verdadeira panaceia para todas as mazelas que infligem a educação brasileira.

Este texto, reconhecendo e reafirmando o papel crucial da reflexão teórica na leitura política do Social, em particular no que tange à desestabilização de discursos hegemonizados nas políticas educacionais curriculares contemporâneas, se propõe a entrar nesse debate tendo como foco a interface currículo-conhecimento-docência. Ele tem por objetivo explorar as articulações entre a produção de currículos de História e os processos de subjetivação política mobilizados pelos/as professores/as que atuam nos Anos Iniciais do Ensino Fundamental, por meio da relação estabelecida com o conhecimento histórico legitimado como objeto de ensino por esses sujeitos.

Nesse movimento procuramos compreender, a partir de uma releitura pósfundacional (GABRIEL, 2018a, 2018b) das categorias 'saber docente' (TARDIF; LESSARD; LAHAYE, 1991; TARDIF, 2002) e 'relação com o saber' (CHARLOT, 2000), a maneira como esses sujeitosposicionados como docentes da educação básica - se inscrevem e participam do jogo político em torno da fixação de sentidos de termos em disputa como, por exemplo: 'currículo', 'conhecimento', 'docência', 'escola', 'conteúdo', 'qualidade', 'justiça social'. Entendemos que ambas as categorias permitem explorar a interface anteriormente mencionada, foco de nossa reflexão.

Convém destacar que a categoria 'saber docente' coloca-nos no epicentro dos debates sobre a singularidade desse ofício e de seus desdobramentos para pensar politicamente o campo. Mobilizada com o intuito de defender a docência como um "ofício feito de saberes" (NUNES, 2001) - disciplinar, curricular, das ciências da Educação, da tradição Pedagógica, da experiência, da ação Pedagógica, para nomear apenas os mais citados -, essa categoria, além de ser adjetivada de plural e heterogênea, é também considerada estratégica, anunciando o lugar crucial ocupado por esses sujeitos-docentes nas lutas pela definição desse ofício que atravessam os currículos de licenciatura e escolar. Investir na ideia de um saber diferenciado e específico do ofício docente foi e continua sendo, assim, uma forma de entrar na disputa tanto do termo docência quanto pela legitimação dos próprios contextos de formação.

No que concerne à segunda categoria - 'relação com o saber' -, entendida, na perspectiva aqui trabalhada, de forma ampla, como uma articulação contingencialmente estabelecida, não apenas com um conteúdo disciplinar específico, mas, também com o outro, com o mundo e consigo mesmo, em um contexto discursivo específico - ela apresenta-se como uma chave de leitura incontornável para a compreensão das estratégias mobilizadas por esses sujeitos em meio às lutas pela significação do próprio campo da docência. Caberia então indagar: no contexto de sua atuação profissional, em que processos de significação 
o/a professor/a da educação básica participa e investe? Que efeitos esse investimento produz nos processos de estabilização e/ou desestabilização de discursos hegemônicos sobre esse ofício?

Esse tipo de questionamento evidencia a hipótese, subjacente à reflexão pretendida, que aposta na potência em trabalhar com duas afirmações de forma articulada: (i) os/as docentes produzem e reinventam currículos no seu cotidiano profissional por meio do tipo de relação estabelecida com o conhecimento na sala de aula e (ii) a agência docente está diretamente vinculada à maneira como esse profissional significa essa relação.

Apoiada no diálogo com as contribuições das abordagens discursivas pósfundacionais (LACLAU; MOUFFE, 2004; MARCHAT, 2009), esta reflexão aposta na importância política da compreensão da natureza da relação estabelecida pelo professor da educação básica com o conhecimento histórico escolar como estratégia possível de deslocamento de processos de significação hegemônicos (GABREL, 2018b) em torno da própria definição dessa profissão.

Desse modo, apostamos na potência heurística de um sentido particular da palavra 'relação' entre sujeitos e saberes para a compreensão da produção de currículos de História outros que os hegemonizados nas atuais políticas educacionais. Interpretamos que o currículo de História legitimado na Educação Básica se define contingencialmente em meio à relação estabelecida pelo docente com o conhecimento histórico escolar. Nessa perspectiva não estamos falando de currículo em geral ou de currículo de História, em particular, como algo coisificado. No tipo de abordagem discursiva, assumida neste texto, o sentido de currículo é fixado como espaço-tempo poroso, permeado por diferentes fluxos de sentidos de 'conhecimento', 'professor', 'aluno', 'história-ensinada'. Definir implica, nesse quadro de inteligibilidade, estancamentos constantes e provisórios de alguns desses fluxos de sentidos particulares em detrimento de outros.

De forma semelhante, entendemos que não existem 'sujeitos/professores da Educação Básica', mais ou menos autônomos, prontos, previamente definidos antes de estabelecerem uma relação com o conhecimento escolar, considerado matéria prima do seu ofício. Afinal, como aponta Retamozo (2011), "a ruptura com os essencialismos e transcendentalismos para pensar os sujeitos nos conduz a considerar a constituição dos sujeitos como inacabados e em processo." (RETAM0Z0, 2011, p. 85). Esses indivíduos posicionados como docentes estão em permanência sendo reafirmados, inventados, investidos, subvertidos e desse modo vão se tornando presença (BIESTA, 2013) e agindo no mundo como 'seressociais singulares' (DELORY-MOMBERGER, 2010) em contextos sócio-históricos específicos.

É, pois, nessa perspectiva que o diálogo entre a teorização do discurso (LACLAU; MOUFFE, 2004; HOWARTH, 2000) e a pesquisa biográfica (NIEWIADOMSKY, 2012; DELORYMOMBERGER, 2010), a partir da postura epistêmica pós-fundacional, tem se apresentado 
promissor. Trata-se de operar com a ideia de currículo como 'espaço biográfico' (AIRFUCH, 2010, p. 16), isto é, como um horizonte de inteligibilidade, no qual é possível pensar de forma articulada os processos de objetivação e de subjetivação tanto do conhecimento a ser ensinado quanto do sujeito que ensina (GABRIEL, 2018a).

A escolha desse recorte apresenta pelo menos dois desafios que merecem ser explicitados desde já. 0 primeiro diz respeito à articulação entre o foco e o referencial teórico-metodológico privilegiados. Assumir a postura pós-fundacional exige trabalhar com linhas investigativas que possibilitem transitarmos "de sistemas de pensamentos baseados em fundamentos transcendentais e metafísicos que explicam a origem do homem, da ciência ou do conhecimento para outras formas de inteligibilidade que sustentam a ausência de fundamentos últimos." (HERNANDEZ, 2014). Estudos que focalizam a interface conhecimentodocência, a partir dessa abordagem, não têm sido um recorte dos mais explorados no campo do currículo. De uma maneira geral, a incorporação nesse campo das teorizações sociais que assumiram a 'virada ontológica'4 tem contribuído para a reflexão curricular, seja sobre a produção da diferença e seus efeitos na estruturação de lealdades identitárias em contextos discursivos particulares (MACED0; RANNIERY, 2018; MACEDO; MLLER, 2018), seja sobre a produção de políticas curriculares oferecendo outras leituras políticas possíveis do social a partir desse campo (LOPES, 2017).

Interessa-nos, por meio da escolha do foco da análise aqui proposta, participar nas disputas pela fixação de sentido de termos, como os mencionados anteriormente, tanto para não deixar cair no esquecimento a natureza provisória e precária de todo e qualquer significado a eles atribuído, isto é, a força da contingência nas lutas políticas, quanto para investir discursivamente na estabilização, sedimentação e hegemonização de sentidos particulares dos mesmos.

0 segundo desafio diz respeito ao recorte disciplinar e o nível de ensino privilegiados nesta análise. Discutir a 'relação com o saber histórico escolar nos Anos Iniciais' implica dialogar igualmente com as contribuições das pesquisas em ensino de História que tenham como foco tanto às questões de ordem político-epistemológica mais gerais que envolvam a produção e distribuição do conhecimento histórico escolar, quanto às relacionadas à singularidade desse nível de ensino.

No que se refere aos aspectos mais gerais, o enfrentamento teórico reside na compreensão das particularidades do jogo político e sua definição, mobilizados na produção do currículo de História e, em particular, do conhecimento histórico escolar. Estudos como

4 Expressão utilizada para nomear uma mudança paradigmática na produção do conhecimento no âmbito das ciências sociais. Em vez de nos limitarmos à compreensão do modo como o existente é conhecido, essa postura epistêmica questiona e problematiza a própria percepção do existente. 
os de Gabriel e Costa (2011), que operam com a abordagem pós-fundacional no campo de pesquisa do ensino em História, apontam que as questões de temporalidade e de identidade/ diferença merecem destaque nessa reflexão. Em seguida, em termos dos aspectos relacionados à especificidade das séries iniciais, trata-se de compreender como se articulam a particularidade do perfil profissional do professor das séries iniciais e as demandas de conhecimento da área de História.

Apesar de a literatura especializada das áreas de História e de Educação apontar um aumento substantivo da produção acadêmica sobre ensino de História, essa não é a tendência observada quando se trata do ensino desta disciplina nos Anos Iniciais. Este nível da Educação básica tende a ser um objeto de reflexão esquecido nos cursos de graduação e de pós-graduação em História. De forma semelhante, essa temática não recebe necessariamente uma atenção especial nos currículos dos cursos de graduação em Pedagogia. Essa situação tende a aumentar o fosso que separa os Anos Finais do Ensino Fundamental e o Ensino Médio dos primeiros anos do Ensino Fundamental. Considerando as várias mudanças pelas quais a sociedade e a produção de conhecimento têm passado e que exigem do professor dos Anos Iniciais "[...] um domínio conceitual no ensino de História, e das outras disciplinas, em que prevaleça a capacidade crítica, a reflexão e a compreensão da dinâmica histórica ao nível da possibilidade do pensamento na infância" (MONTEIRO, 2007, p. 59), bem como a importância desse segmento para a trajetória escolar, essa escassez de estudos merece ser problematizada. 0 recorte privilegiado, neste texto, tanto situa a reflexão na contramão das tendências de pesquisa na área quanto reconhece a complexidade que ela encerra.

Em linhas gerais, é possivel identificar, nos estudos sobre o ensino de História nos Anos Iniciais, três aspectos relacionados à singularidade desse segmento da educação básica e que retomaremos - ainda que não com a mesma ênfase - ao longo deste texto: o perfil polivalente do/a professor/a que atua nesse segmento; os desafios da aprendizagem de História nos Anos iniciais, tendo em vista a faixa etária dos estudantes e os desafios que esses dois aspectos impõem ao processo de reelaboração didática da história-ensinada nesse nível de ensino.

0 primeiro aspecto remete aos currículos de Licenciatura em Pedagogia e aos debates acadêmicos sobre o perfil profissional do pedagogo/a. Como pensar a relação com o conhecimento histórico produzida pelos/as professores/as dos Anos Iniciais quando esses/ as não são professores/as especialistas, não foram portanto formado/as para lecionar somente História? São professores/as multidisciplinares e, nesse contexto, são também docentes de História. 0 segundo diz respeito aos debates internos ao campo da pesquisa em ensino de história sobre a pertinência do ensino e a possibilidade de aprendizagem dessa disciplina no primeiro segmento da educação básica quando confrontamos a complexidade de conceitos como por exemplo 'tempo histórico', 'sujeito histórico' ou 'fonte histórica' - mobilizados 
para a compreensão dos múltiplos processos históricos instituintes das diferentes ordens sociais - e a capacidade de abstração de crianças de seis anos a nove anos. Por fim o terceiro aspecto refere-se ao processo de produção do conhecimento histórico escolar nesse contexto discursivo específico nos quais os sujeitos - docentes e discentes - apresentam singularidades, tais como apontadas nos dois primeiros aspectos. Entre elas, destaca-se a questão dos impactos da integração disciplinar no processo de ensino-aprendizagem desse segmento, trazendo à tona um debate clássico nessa área em torno da pertinência política, epistemológica e pedagógica dos Estudos Sociais.

Selecionamos como campo empírico para análise um conjunto de narrativas produzidas por oito docentes que atuam nos Anos Iniciais com trajetórias de formação inicial diferenciadas ${ }^{5}$ e cujas práticas profissionais exercidas em culturas escolares distintas têm, em comum o fato de serem reconhecidas, pelos seus próprios pares, como positivas e instigantes no que diz respeito ao ensino de História nesse nível de ensino. Esses fragmentos de narrativa produzidos por esses docentes são mobilizados ao longo do texto, como mais uma voz que dá corpo à figura deste ator social e que se entrelaça com outras - inclusive a das autoras - na tessitura da trama da interdiscursividade aqui narrada. ${ }^{6}$ As vozes e silêncios dos professores/as entrevistados/as trazidos para compor a tessitura deste texto falam de estabilidades e tensionamentos que instituem e atravessam os currículos de História e da capacidade de agir desses sujeitos que produzem e vivenciam essas tensões.

Escolhemos dois pontos/nós dessa trama para serem explorados a seguir. 0 primeiro faz referência às estabilidades e às tensões que atravessam a produção do conhecimento escolar no âmbito do currículo de História das séries iniciais a partir da perspectiva teórica-metodológica privilegiada. 0 segundo focaliza a relação que esses sujeitos, posicionados como professoras dos Anos Iniciais, estabelecem com o conhecimento histórico e os efeitos que a mesma produz no entendimento de agência docente. 


\section{CONHECIMENTO HISTÓRICO ESCOLAR NOS CURRÍCULOS DOS ANOS INICIAIS: ESTABILIDADES E TENSÕES}

Qual o conhecimento histórico escolar que integra o currículo dos Anos Iniciais? Ou, formulado de outro modo, o que é significado como relevante para ser ensinado aos/às alunos/as desse segmento? Quem decide o que é ou não é relevante para formação nesse contexto discursivo específico? Qual a articulação que esse conhecimento escolar legitimado e validado como objeto de ensino-aprendizagem desse segmento estabelece com a ciência histórica? Como esse conhecimento curricularizado satisfaz as demandas de igualdade e de diferença que interpelam a história em nosso presente? Essas são apenas algumas das inúmeras questões que emergem quando nos propomos a compreender o processo de produção do currículo histórico endereçado às crianças escolarizadas nos Anos Iniciais.

Em diálogo com a abordagem discursiva pós-fundacional, longe de pretender reafirmar 'a' definição mais correta, interessa-nos puxar alguns fios que permitam evidenciar o jogo político que atravessa o processo de definição do que está sendo chamado e o do que não está sendo chamado de 'conhecimento histórico escolar' do Anos Iniciais. Afinal, dependendo da perspectiva historiográfica privilegiada, das definições de escola e de ensinoaprendizagem com as quais se opera, ou ainda, dos interesses políticos em jogo, da escolha do 'ângulo de ataque' para entrar na discussão, o entendimento desse termo varia, deixando entrever as múltiplas possibilidades de definição, sempre abertas.

Para fins deste estudo, operamos com a ideia de que o sentido de 'conhecimento histórico escolar' pode ser entendido como um 'conhecimento disciplinarizado' (GABRIEL; FERREIRA, 2012) resultante de um processo permanente de curricularização e de didatização da "cultura histórica" nas tramas da "cultura escolar" (GABRIEL, 2015).

A expressão 'cultura escolar' é empregada, nesta reflexão, para pensar e definir as coisas de escola. Essa perspectiva abre possibilidades de definir o escolar de forma a considerar as especificidades estabilizadas contingencialmente desse tempo-espaço colocando em evidência a importância da relação com o conhecimento nesse contexto discursivo. Isso significa olhar a escola sem buscar sua essência, sua positividade plena e transparente, mas olhá-la por aquilo que o escolar exclui, deixa de fora, ou seja: seu exterior constitutivo (o não-escolar). Entre às múltiplas e infinitas possibilidades de fixação de sentido presentes nas lutas pela significação de escola ou escolar, interessa-nos destacar o seu entendimento como lócus de socialização e de democratização do conhecimento científico, neste caso, do conhecimento histórico. Dito de outra forma, os saberes produzidos na e pela escola, embora apresentem especificidades e contornos epistemológicos próprios, não estão 
dissociados dos saberes acadêmicos, tampouco das demandas formuladas pelos diferentes grupos de interesse que disputam projetos de sociedade e de escola.

Não se trata de reforçar hierarquias entre os diferentes conhecimentos, mas sim considerar o papel desempenhado pelo conhecimento científico na produção do conhecimento escolar. Cabe lembrar igualmente que Ciência é um termo em torno do qual se disputam sentidos de verdade. Assumir a centralidade do papel dos fluxos de cientificidade na definição de conhecimento escolar significa assumir o compromisso da escola com os diferentes regimes de verdade contingencialmente hegemonizados das áreas de conhecimento reconfiguradas em conhecimento escolar. Dito de outro modo, significa reconhecer que o conhecimento escolar se inscreve no domínio daquilo que é considerado pelos debates epistemológicos da área como contingencialmente verdadeiro.

De modo semelhante, a expressão 'cultura histórica' tem como função discursiva, na análise proposta, condensar a ideia de temporalidades como um possível fechamento provisório do que seria história ou conhecimento histórico. Afinal, a história é uma forma de visitar o passado e projetar o futuro a partir de cada presente. Ela interpreta e explica o mundo social no âmbito de um determinado "regime de historicidade", isto é, dos diferentes modos de articulação das categorias de presente, de passado e de futuro (HARTOG, 2007, p. 16).

Nessa perspectiva, a análise busca explorar algumas linhas de força que participam desse processo de significação em um espaço-tempo específico - cultura histórica escolar hegemonizada em nosso tempo presente nos currículos dos Anos Iniciais - sublinhando tanto aquelas que contribuem para a estabilidade e hegemonização provisórias de narrativas históricas, recontextualizadas no processo de ensino-aprendizagem, quanto aquelas que antagonizam ou deslocam tais discursos.

A presença relativamente estável da disciplina de História nos currículos da educação básica, se comparada a outras áreas do conhecimento no campo das ciências sociais, pode ser vista como um indício de estabilidade de determinados discursos que têm contribuído para a sua definição ou para o entendimento de sua 'razão de ser' ao longo da trajetória dessa disciplina. Todavia essa permanência não significa necessariamente poder e prestígio inconteste. Basta evocarmos a distribuição da carga horária ou o peso atribuído às avaliações entre o conjunto das disciplinas que configuram os currículos escolares para nos darmos conta de que a disciplina História ocupa um "lugar menor" em relação às disciplinas como a Matemática e a Língua portuguesa.

Essa estabilidade se explicaria, menos por um movimento de subversão das relações de poder assimétricas e hierarquizadas entre as diferentes áreas do conhecimento científico no âmbito da cultura escolar do que, pela continuidade da presença da história como 'matéria' da educação básica. As disputas que marcaram os anos de 1980 pelo fim dos Estudos Sociais e 
pelo retorno da História e da Geografia nos currículos escolares traduziram, de forma inequívoca, a força da comunidade disciplinar dessa área do conhecimento para se manter nos currículos da educação básica. Bittencourt (2004) nos oferece elementos importantes de reflexão sobre a natureza dessa estabilidade. Para essa autora, a disciplina História

\footnotetext{
[...] tem permanecido nos currículos escolares dos diferentes níveis do ensino básico e também como matéria dos cursos preparatórios ou de exames vestibulares brasileiros. A História escolar integra o conjunto de disciplinas que foram sendo constituídas como saberes fundamentais no processo da escolarização brasileira e passou por mudanças significativas quanto a métodos, conteúdos e finalidades até chegar à atual configuração nas propostas curriculares. (BITTENCOURT, 2004, p. 33, grifo nosso).
}

Essa inscrição da disciplina História no grupo de 'saberes fundamentais' pode ser compreendida pela dupla natureza - epistemológica e axiológica - do conhecimento histórico desde sua instituição como disciplina, no século XIX. Essas duas dimensões, embora não exclusivas dessa área do conhecimento, se apresentam intrinsecamente articuladas no campo da história sendo objeto de problematização das teorizações da área. A dimensão axiológica está, nessa área, diretamente vinculada à própria justificativa de existência dessa disciplina. Como apontam estudos curriculares que focalizam a história das disciplinas (CHERVEL, 1990; BITTENCOURT, 2004), o caso dessa área disciplinar é emblemático para a compreensão dos efeitos produzidos pela ordem social mais ampla sobre a cultura escolar. A trajetória da 'disciplina história' traz como marca de sua singularidade a simultaneidade entre a sua incorporação nos currículos oficiais e a emergência e consolidação do Estado Nacional. Era preciso inventar um passado comum à nação brasileira emergente e a disciplina escolar de História desempenhou bem essa função ao contribuir para a fixação de uma memória nacional produzida no âmbito das matrizes historiográficas predominantes na época que traduziam a articulação de narrativas do passado de grupos de interesse hegemônicos.

Ao longo do século XIX o papel ordenador e civilizador da história ensinada nas escolas, na pauta do positivismo, vai se delineando com mais clareza. Os livros didáticos de História do Brasil, da época, como os de autoria de Rocha Pombo, entre outros, traduziam bem essa dimensão axiológica presente no ensino desta disciplina. A incorporação de contribuições de novas matrizes historiográficas no processo de produção do conhecimento histórico escolar, ao longo dos séculos XX e início do XXI, não significou o fim dessa dimensão. Assistese, todavia, um deslocamento dos valores legitimados para comporem os currículos de história. A defesa de uma moral cívica enaltecedora da pátria é substituída por princípios éticos que se manifestam, seja pela ideia de mudança e de transformação social revestidas do objetivo de formar 'cidadãos críticos' assumido como um verdadeiro mantra pelos professores de história (VELASCO, 2013), seja pela incorporação, mais recente, nos currículos dessa disciplina das 
demandas de diferença formuladas no seio de movimentos sociais que interpelam a instituição escolar em nossa contemporaneidade. Afinal, desenvolver o senso crítico, aprender sobre sua história, ou seja, seu país e a história no todo é tornar um indivíduo crítico e reflexivo. Do mesmo modo, fazer uma leitura de mundo, uma leitura mais crítica, aprender a conhecer a realidade que ele tem e o que pode fazer para mudar, [...] fazem parte do horizonte de expectativas do profissional dessa área e para tal, o/a aluno/a precisa ter a capacidade de ser crítico. Embora, no primeiro segmento não se consiga fazer com que o aluno/a tenha a maturidade suficiente para definir tudo, se ele começar a ver o que é o melhor [...] o que é mais produtivo... o que não é... o ensino desta disciplina vai estar contribuindo para formação de um cidadão crítico. Outro desafio relacionado à dimensão axiológica é essa questão da diversidade, da diferença, porque hoje sabemos que existe com mais clareza. Você não tinha tanto isso, cada vez mais a questão da diferença e a importância de um ensino de História que invista no respeito às diferenças se apresentam como um imperativo na prática profissional docente.

Os efeitos desse duplo registro nos processos de seleção e de reelaboração didática assumem configurações diferenciadas. Algumas formulações na articulação entre valores, conteúdos/conhecimentos e criticidade na produção dos conhecimentos escolares. Afinal é preciso trabalhar a argumentação, já que se ele não tiver conhecimento, ele não tem nada. Ele não vai saber argumentar, ele não vai ser um cidadão crítico, já que para fazer a crítica você tem que ter conhecimento. A gente tem que trazer também conhecimento de mundo para ele, não partir só do que ele traz, tem que enriquecer e ampliar esse mundo que ele vive e que conhece. 0 papel do docente nesse processo é contribuir para a formação desse cidadão crítico, por meio da socialização e da distribuição desses conhecimentos para analisar, para selecionar, para argumentar, para transformar e para fazer as escolhas dele como cidadão

No entanto, esse tipo de entendimento não é consensual, tampouco hegemônico. As dimensões axiológica e epistemológica tendem, muitas vezes, a ser mobilizadas de forma dicotômica. Ciência e arte/literatura, verdade e valores, história e memória, explicação e compreensão são alguns binarismos bastante mobilizados nos debates historiográficos que se recontextualizam na cultura histórica escolar de nosso presente. Ora para criticá-los, ora para superá-los ou buscar caminhos para fazer trabalhar essas aporias de forma não dicotômica, a 'cultura histórica' - acadêmica e escolar - por meio das suas diferentes vertentes historiográficas - é atravessada por essas tensões.

A despeito das formas de mobilização e articulação dessas duas dimensões na configuração do conhecimento escolar, é possível observar elementos de estabilidade na produção desse conhecimento que dizem respeito às formas de reconfiguração didática de duas categorias estruturantes do pensamento histórico 'tempo/temporalidade' e 'identidade/diferença'. 
Em relação ao eixo das temporalidades, importa sublinhar que a crítica a uma certa forma de conceber o tempo histórico na matriz positivista e eurocêntrica não significou a negação da importância da reflexão sobre a temporalidade como elemento definidor da ciência histórica. A questão do tempo, a despeito da matriz historiográfica na qual ela é trabalhada, permeia todos os anos escolares. Assim, seja para compreender todo o processo histórico desde a Antiguidade até os dias atuais e fazer ligação entre eles, seja para trabalhar noções temporais como mudança, permanência duração, simultaneidade... o tempo é uma variável sempre presente na história ensinada nas séries iniciais da educação básica. Mesmo reconhecendo as dificuldades de aprendizagem do tempo nas séries iniciais, é possível perceber um consenso entre as professoras entrevistadas em torno do investimento imprescindível nessa noção, por meio do trabalho com as linhas de tempo e com todas as relações temporais para que os / as alunos/as possam entender que as coisas podem acontecer ao mesmo tempo, coisas acontecem, o que aconteceu antes e o que aconteceu depois.

De forma semelhante, essa interpretação também cabe para o eixo das identidades/ diferença. Embora, nas últimas três décadas - em parte pela especificidade do sentido a ela tradicionalmente atribuído nessa disciplina escolar, em parte pelos ares de nossos tempos - a identidade nacional tenha se tornado alvo de críticas e suscitado posicionamentos distintos entre os pesquisadores sobre a validade política e epistemológica dessa marca identitária, os processos de identificação permanecem um eixo igualmente estruturante da reflexão histórica em sua versão escolar. A ampliação das marcas de lealdade disponíveis (individual, cultural, diferentes escalas territoriais) não significou um enfraquecimento desse eixo estruturante. 0 ensino da história é importante na construção da noção de identidades individuais e sociais.

Nos anos iniciais, essa questão é mobilizada como estratégia tanto de construção de identidades individuais dos/as alunos/as quanto de fortalecimento do sentimento de pertencimento a determinados grupos territoriais. Não é por acaso que trazer as histórias da família pra dentro da escola, as suas histórias particulares com o intuito de criar a identidade deles é um dos objetivos mais recorrentes nesse nível de ensino. É comum nos fragmentos narrativos das professoras com as quais conversamos, o reconhecimento da importância de trabalhar bastante com os relatos dos avós para contarem como era na época da infância deles, as brincadeiras, com objetos, com as fontes mesmo da história das respectivas familias das crianças.

Para além dessas linhas de estabilidade na configuração do currículo de História, é perceptível um ponto de tensão em torno da pertinência ou não em operar com a integração disciplinar das ciências sociais nesse nível de ensino. Para os defensores dessa integração, ela é intrínseca à construção de conhecimento e determinante para a sua aprendizagem nos Anos Iniciais. Nessa perspectiva, predomina a referência à articulação entre História e Geografia, sendo significada como aquilo que consegue dar um sentido mais claro para o 
trabalho, se manifestando na mobilização dos conceitos de tempo e espaço, ou melhor, das coordenadas espaciais e temporais. 0 objetivo principal do processo de ensino-aprendizagem é fazer com que a pessoa se perceba enquanto um ser histórico e um ser geográfico. Embora se reconheça a complexidade desses dois conceitos para a faixa etária dos/as alunos/as dos Anos iniciais, tanto as relações temporais, quanto as relações espaciais são os dois conteúdos fundamentais para trabalhar com eles.

Esse tipo de integração está presente quando se procura definir os conteúdos históricos em torno de alguns eixos que precisam ser trabalhados de forma articulada. Afinal quando se fala em espaço, Isel pensa em localização, em limites, vizinhança, proximidade, coordenada nas relações de inclusão, nas transformações que este espaço vem sofrendo, nas formas de uso desse espaço, os prejuizos, a relação com o meio ambiente. Quando se fala de grupos sociais, trata-se das relações de poder, da política, dos dominados, dos dominantes, de como essas sociedades se organizaram, de como é que os grupos se relacionam entre si l...] A questão do tempo remete muito a essa noção mesmo de construção de décadas, séculos, linha de tempo, com a questão da sociedade, com as mudanças ocorridas na sociedade.

A tensão entre recorte disciplinar e interdisciplinar, tal como debatida no âmbito do ensino das séries iniciais, remete, por sua vez, ao percurso formativo oferecido pelos currículos de Pedagogia nos quais são produzidos e hegemonizados sentidos de identidade profissional para os docentes que atuam nesse nivel de ensino. Oliveira (2003), ao se interrogar justamente sobre o lugar do ensino de História nas séries iniciais, traz para o debate alguns elementos que marcam a especificidade dos sujeitos posicionados tanto como docentes quanto discentes. Partindo de questionamentos, tais como: "Quais as representações que os professores generalistas têm da História, do passado, do ensino de História?" (OLIVEIRA, 2003, p. 159). "Qual a compreensão que um aluno de sete, oito anos pode formular a respeito da História, do passado?" (OLIVEIRA, 2003, p. 159) essa autora aborda questões cruciais para a compreensão da produção do currículo de história nesse segmento do ensino fundamental na medida em que incidem diretamente sobre a relação com o conhecimento histórico estabelecida por esses sujeitos.

Na próxima seção interessa-nos puxar ○ fio da trama problematizada na primeira questão. Afinal, como se constrói a relação entre um professor não especialista e um conhecimento disciplinarizado? Que efeitos esse tipo de relação produz na participação desses sujeitos nas disputas políticas pela hegemonização do conhecimento histórico escolar? Que traços de agência docente é possivel perceber nessa relação? Esse tipo de questionamento é ainda mais pertinente com o término dos Estudos Sociais, traduzindo 0 "desejo dos especialistas" (OLIVEIRA, 2003, p. 263), e o retorno das disciplinas História e Geografia nos currículos das séries iniciais a partir do final dos anos de 1990. 


\section{TORNANDO-SE PROFESSORES DE HISTÓRIA DOS ANOS INICIAIS}

\footnotetext{
[...] poderíamos argumentar que o conjunto de capacidades inerentes ao sujeito - ou seja, as capacidades que definem os modos da sua agência - não são o resíduo de um self não domesticado, existente antes das operações de poder, mas são, em si mesmas produto dessas operações. Este entendimento do poder e formação do sujeito permite-nos conceitualizar a agência não só como um sinônimo de resistência a relações de dominação, mas também como uma capacidade para ação criada e propiciada por relações de subordinação específicas. (MAHM00D, 2006, p. 132).
}

Trouxemos como epígrafe desta seção o entendimento de Mahmood (2006) sobre a categoria 'agência', na medida em que consideramos que, ao articular 'capacidade de agir' e 'subordinação' para além da concepção binária de resistência/sujeição, essa autora abre pistas de investigação para a reflexão aqui pretendida, em particular no que diz respeito à sustentação das hipóteses que a subjazem.

Nessa linha argumentativa, entendemos que a ação de 'tornar-se professor' opera na lógica do 'paradoxo da subjetivação' presente na premissa foucaultiana. Isso significa que essa ação pode ser compreendida como um movimento que simultaneamente garante a subordinação dos sujeitos às relações de poder e produz os "meios através dos quais ele se transforma numa entidade consciente e num agente." (MAHMOOD, 2006, p. 121). Assim, o poder como relação de forças estratégicas não atua somente no sentido de dominar, ele também é produtor de formas de desejo, discursos, relações.

Nessa concepção, o tornar-se professor da educação básica dos anos iniciais é diretamente dependente da norma ou estabilidades que regulam esse ofício. 0 desafio consiste em compreender as práticas de subjetivação que tornam possiveis os sujeitos tornarem-se professor/a dentro de uma formação discursiva específica - o magistério nas séries iniciais - por meio do exame das práticas discursivas e performativas que viabilizam a filiação dos sujeitos a uma normatividade que fornece, ela mesma, as condições necessárias para a subordinação e para a agência. Afinal, como argumenta Butler (2014), a norma governa a inteligibilidade social da ação que não é o mesmo que a ação governada por ela.

Assim, o que significa agir politicamente do lugar da docência? De que maneira os sujeitos posicionados como docentes do primeiro segmento do ensino fundamental participam das lutas pela significação que envolvem a definição de seu próprio ofício? 
Se considerarmos a estruturação desigual, hierárquica e excludente do sistema de conhecimento hegemonizada na ordem social na qual nos movemos, é possivel perceber que a interface docência-conhecimento tende a ser vista como um "lugar menor", um campo discursivo de menor prestígio quando comparada com outras posições de sujeito que se relacionam igualmente com o significante-conhecimento, como, por exemplo, a figura do/a pesquisador/a. Os 'saberes objetos-de ensino' da educação básica, matéria prima do ofício docente, assim como a própria profissão do professor, tendem a ser desvalorizados. Paradoxalmente é a relação estabelecida com esses mesmos saberes que explica o lugar político estratégico que ocupa esse profissional na sociedade contemporânea. Afinal, ele socializa um dos bens culturais mais desigualmente distribuídos em nosso país. Como operar com a tensão entre a desvalorização dos saberes docentes e o reconhecimento do papel estratégico desse profissional? Como deslocar pois, o sentido hegemonicamente fixado de 'docência' de um 'lugar social subalternizado' para um lugar de produção de subjetividades politicas rebeldes' sem participar das disputas pela significação da relação que essa profissão estabelece com o conhecimento?

A aposta, aqui sustentada, reconhece essa impossibilidade. Ela se pauta na ideia de que, sem um enfrentamento com a ordem social hierarquizada do sistema de conhecimento historicamente hegemonizado no qual a normatividade da docência é produzida, fica difícil deslocamentos ou produção de antagonismos que coloquem no jogo político outras definições possíveis. Operando, como mencionado, com a compreensão de 'agência' como "capacidade de ação criada e propiciada por relações concretas de subordinação historicamente configuradas" (MAHM00D, 2006, p. १२3), entendemos que a maneira como esses profissionais significam a relação com o conhecimento histórico, estabilizado contingencialmente, propicia a sua ação criativa, a sua capacidade de produzir e reinventar currículo no seu cotidiano profissional.

No caso dos professores que atuam no primeiro segmento do ensino fundamental, 'as relações concretas de subordinação historicamente configuradas' específicas no âmbito dessa profissão apresentam uma particularidade, na medida em que esses profissionais são subalternizados no próprio campo discursivo da docência. Essa situação de dupla subordinação está vinculada diretamente à natureza da formação inicial desse profissional.

Com efeito, a formação inicial generalista que caracteriza os cursos de licenciatura em Pedagogia produz efeitos na atuação desse profissional, em particular, no que incide no processo de reelaboração ou de reconfiguração didática do conhecimento científico validado pelos regimes de verdade dos diferentes campos de conhecimento em objeto de ensino para as séries iniciais. Um dos maiores desafios, portanto, dos professores das séries iniciais diz respeito ao diálogo inevitável, embora não exclusivo, no processo de produção do conhecimento escolar, com os saberes de referência de uma área disciplinar específica. Essa particularidade do 'saber docente' construído no âmbito dos currículos dos cursos de 
Pedagogia inscreve-se em meio às disputas históricas do campo educacional sobre a própria identidade profissional do pedagogo (PUGAS, 2013; DIAS, 2018). Não cabe, nos limites deste texto, nos aprofundarmos nessas celeumas. Por ora, interessa-nos explorar os efeitos, sobre a produção da subalternidade, das lutas pela hegemonização de um sentido particular desse perfil profissional que ocorrem na fronteira que diferencia 'pedagogo' e 'docente'.

Diferentemente dos professores especialistas que atuam no segundo segmento do ensino fundamental e no ensino médio, os docentes-pedagogos não têm um espaçotempo ao longo de seu percurso formativo para trabalhar com os saberes disciplinares de referência. Embora a presença de disciplinas das áreas de conhecimento específica no currículo das demais licenciaturas não seja necessariamente suficiente para garantir um deslocamento do lugar subalterno atribuído à docência, essa marca dos cursos de Pedagogia dificulta ainda mais, que esses/as professores/as se percebam e sejam percebidos/as como produtores/as de conhecimento, "uma vez que o saber dos professores que aí atuam parece residir unicamente na competência técnica e pedagógica para transmitir saberes elaborados por outros grupos." (TARDIF, 2002, p. 35).

A esse quadro, soma-se o não reconhecimento dos saberes pedagógicos como integrantes do conjunto das ciências sociais, limitando sua filiação ao domínio da axiologia e/ ou da prática, entendida essa última, como um verdadeiro 'vazio epistemológico'. Reduzidos a reprodutores e transmissores de saberes produzidos em outros contextos discursivos, esses/as docentes tendem a ocupar as posições mais desvalorizadas de uma profissão cuja imagem já está desgastada em nossa sociedade. Essa hierarquia entre os segmentos que compõem a Educação Básica contribui para uma maior desvalorização e o desmerecimento do trabalho desse docente. Em uma escala de importância, a Educação Infantil e os Anos Iniciais são os segmentos menos reconhecidos, por parte dos pais e da sociedade, que veem a Educação Infantil como o espaço meramente do cuidar, em que as crianças são deixadas, enquanto os pais trabalham fora, para ganhar o sustento de cada dia.

Tendo em vista o recorte privilegiado e a partir da postura epistêmica assumida nessa escrita, apostamos na articulação das categorias 'saber docente' e 'relação com o saber' como chaves de leituras fecundas para a compreensão das estratégias mobilizadas, desde o lugar de professor/a dos anos iniciais, para desestabilizar essas relações assimétricas.

Longe de assumir verdades absolutas e prescritivas sobre a interface 'relação com o saber' e 'ação docente', a análise pretende mostrar traços de possíveis formas de agenciamento desse profissional que podem abrir pistas para futuras investigações. Como os/as docentes das séries inicias habitam os currículos de História legitimados para serem ensinados e aprendidos nesse nível da Educação Básica. Como eles lidam com as forças da 
tradição no campo da História? Como eles as ressignificam? as incorporam? Que rotas de escape eles produzem ou trilham na relação com esse conhecimento disciplinar?

Uma análise não sistemática dos estudos acadêmicos que têm como foco o ensino de História nesse segmento de ensino permite destacar três discursos recorrentes sobre a natureza da relação com o conhecimento histórico estabelecida por esses profissionais. 0 primeiro refere-se à fragilidade teórica da relação que esses docentes estabelecem com o conhecimento histórico de referência. Essa fragilidade tende a se justificar pela formação generalista que caracteriza esse profissional e é responsável pela ênfase dada às dimensões axiológica e pedagógica na relação estabelecida com o currículo de História da educação básica. 0 segundo faz menção à dimensão de exterioridade que caracteriza a relação dos professores com os saberes disciplinares. Para Tardif (2002) os docentes não têm sido responsáveis pela seleção e definição dos saberes que transmitem. 0s mesmos, neste contexto, não têm controle, direta ou indiretamente, sobre as escolhas do que será ensinado no âmbito escolar. 0 terceiro se relaciona ao lugar crucial atribuído à dimensão interdisciplinar na relação que esses sujeitos estabelecem com o conhecimento histórico escolar. Esse lugar de destaque à interdisciplinaridade tende a ser visto nos estudos da área, menos como uma força criativa do contexto discursivo onde ela é pensada do que, como um sinal de inconsistência disciplinar a ser combatida.

Para fins dessa análise, não interessa posicionarmo-nos em relação ao grau de veracidade desses discursos. Entendemos que são interpretações possíveis em meio a uma infinidade de possibilidades outras. Elas falam mais da normatividade que regula o currículo de história dos anos iniciais do que da agência dos docentes que neles habitam.

Procuraremos a seguir apresentar outras interpretações igualmente possíveis, a partir dos sentidos atribuídos pelas professoras entrevistadas às suas próprias práticas. Se concordarmos que "não são os indivíduos que têm experiência, mas os sujeitos é que são constituídos através da experiência" (SCOTT, 1999, p. 5), interessa-nos perceber como esses oito indivíduos entrevistados foram se tornando professoras a partir da forma como eles lidam e significam as práticas vivenciadas no seu cotidiano profissional. Larrosa (2002), ao defender que o 'saber da experiência' pode ser visto não como um saber adquirido a partir do que acontece nas práticas pedagógicas cotidianas, mas sim a partir de como os indivíduos posicionados como docentes respondem ao que vai thes acontecendo ao longo de sua trajetória profissional, contribui para reafirmar essa mesma linha de argumentação. Para esse autor, "a experiência não é o que acontece, mas o que nos acontece." (LARROSA, 2002). Essa definição permite redimensionar a ideia de reflexividade presente nesses debates, sem reatualizar o seu entendimento como algo da ordem da introspecção individualista desprovido de criticidade.

Defendemos, assim, que o 'saber da experiência' não é apenas mais um saber entre os diferentes saberes que configuram o saber docente. Ele é uma perspectiva para 
ver os processos de subjetivação, na medida em que "reintroduz o lugar do sujeito em seu duplo-sentido: como sujeito-sujeitado e como sujeito-agente." (RETAMOZO, 2013, p. 343). Parafraseando Larrosa (2002), a experiência e o saber que dela deriva são o que permite aos docentes habitarem essa cultura profissional.

Desse modo, o conjunto de fragmentos de narrativas docentes que constituíram nosso campo empírico é percebido como o enfoque escolhido para a análise dos processos de subjetivação desses profissionais na perspectiva defendida por Retamozo (2013). Isso significa que essas narrativas apresentam traços tanto do sujeito-sujeitado quanto do sujeito-agente. Ora, elas investem na normatividade hegemônica definidora do currículo e da docência em História nesse segmento da educação básica, ora elas permitem pensar outras interpretações ou problematizar as que se apresentam como cristalizadas no campo de pesquisa dos anos iniciais.

Em relação ao primeiro discurso recorrente, anteriormente mencionado, que diz respeito à fragilidade teórica do tipo de relação estabelecida com a ciência histórica em função da formação generalista que recebem, foi possivel 'capturar' sinais que colocam em questão esse tipo de afirmativa. Se por um lado, o silêncio, a demora excessiva, as repostas evasivas às indagações sobre as correntes historiográficas que influenciavam suas práticas de ensino, podem ser percebidas como pouca familiaridade com as questões epistemológicas do campo da História, por outro lado elas mostraram igualmente estarem antenadas com os debates historiográficos atuais, além de reconhecerem a importância de dialogar com os mesmos.

Assim, embora a questão relacionada à influência das correntes historiográficas fosse muito dificil e complicada de ser respondida, ou algumas respostas associassem correntes historiográficas à produção de materiais didáticos e à pesquisa da prática docente, a articulação com a ciência histórica aparece claramente quando se trata da reflexão temporal, da importância do trabalho com as fontes, da operacionalização da articulação entre diferentes escalas temporais e espaciais, ou ainda da incorporação de matrizes historiográficas mais recentes.

Em relação ao tempo histórico, ou melhor, à sua reconfiguração didática, a percepção das mudanças ocorridas no seio do debate historiográfico e seus efeitos para configuração do currículo escolar nessa área disciplinar está presente na falas dessas professoras, indicando uma maior porosidade entre os saberes de referência e os saberes escolares do que se tende a afirmar. Se no início havia uma preocupação de trabalhar principalmente a história de forma linear traduzida com frequência nas falas das professoras por proposições como por exemplo: não vamos falar desse assunto no primeiro, não fala do que aconteceu no passado porque eles não estão prontos, ou ainda então a gente só vai tratar desse assunto a partir do terceiro ano, essa percepção vai mudando e dando lugar a partir dos anos 90 a outra forma de ver, a possibilidade de trabalhar com assuntos complexos 
no momento considerado viável independente de ser algo destinado a ser ensinado em função da cronologia ocidental clássica que até hoje impera no campo do ensino em História. Você começa, por exemplo, a trabalhar o Rio Colonial, fala do período Passos, que mudou, alterou aquele Rio, aquela configuração... Mas como é que essa cidade começou? Vamos voltar no tempo? Dá pras crianças voltarem. Você não precisa começar com a fundação da cidade.

Em vez de um ensino de História com o objetivo de fazer o/a aluno/aluna compreender todo o processo histórico desde a Antiguidade até os dias atuais e fazer ligação entre eles, o que passa a ser objeto de 'ensinagem-aprendizagem' (LIMA, 2019) e/ ou de reflexão para os docentes é menos a linearidade do tempo - percebida como a única matriz geradora da leitura política do social - do que o próprio trabalho com as diferentes dimensões e variáveis do tempo.

No que diz respeito à abordagem micro e macro e sua repercussão nos debates historiográficos acirrados sobre a tensão entre o ensino de História de escala nacional e/ou de escala local reatualizando uma das tensões clássica - entre o universal e o particular da produção desse conhecimento, a perspectiva de trabalhar com a história do Estado, do Município sem esquecer a do Brasil, já que não existe história desvinculada do Brasil nem do mundo indica um posicionamento claro nas narrativas dessas professoras.

0 trabalho com as diferentes fontes - condição incontornável da produção da ciência histórica - como caminho de apropriação de desse conhecimento e ponto de partida para dosar, conduzir o ensino de História nas aulas dos anos iniciais é outro ponto de aproximação entre essas duas esferas de problematização - pesquisa e ensino - do conhecimento histórico reativado nas narrativas das professoras.

Se em alguns depoimentos o lugar de importância atribuído ao ensino de datas comemorativas aponta a presença de matrizes historiográficas obsoletas no debate epistemológico contemporâneo, merece igualmente destaque as narrativas que incorporaram outras matrizes historiográficas, em particular aquelas que permitem trabalhar a temática do cotidiano nessas séries, como deixa entrever a utilização da obra acadêmica História da Vida Privada como material de consulta para elaborar a aula sobre o Estado do Rio de Janeiro, principalmente no século XIX.

No que diz respeito ao tipo de relação com o saber disciplinar marcada pela exterioridade como apontada por Tardif (2002), as narrativas mostram que esses professores exercem a sua reflexividade de forma contextualizada em função das singularidades e constrangimentos da cultura escolar. Na contramão dos discursos que afirmam que há pouca ou nenhuma resistência por parte das professoras dos Anos Iniciais quanto ao currículo prescrito pelos referenciais que os municípios trazem, os fragmentos de narrativa, objeto de nossa análise, apontam que a prática profissional dessas professoras está muito distante 
de uma mera "reprodução" de saberes oriundos de documentos legais, livros didáticos e calendário cívico. Afinal, a transposição didática desses saberes, junto com as Diretrizes Curriculares e com os conhecimentos que eles trazem é um processo reflexivo constante. Isso implica -para mim como professora - um processo de pesquisa de informação constante em vários lugares, em livros, em vídeos, documentários.

A questão da exterioridade que caracterizaria a relação com o saber disciplinar que elas estabelecem é claramente contestada. Se você me perguntar como é que é a minha prática, como é que leul trabalho, leul vou te dizer que são saberes que leul internalizei, que leul acumulei ao longo da minha vida, de todas as formas. Mas na verdade, eu tenho quatro pontos que sempre nortearam a minha prática: para quem eu estou trabalhando, o que eu estou passando, porque eu estou passando isso e de que forma que eu estou passando isso. Sempre um exercício de reflexão sobre a minha ação, durante a minha ação e depois da minha ação. [É quel eu volto, eu retorno, eu refaço e eu faço todo o meu trabalho. Às vezes durante a atividade eu vejo que não ficou legal, não está fluindo, então eu mudo, eu troco. Às vezes eu penso a coisa de um jeito e quando chego na sala em contato com os alunos, a coisa muda um pouco, às vezes foge e pega outro rumo, mas eu vibro com isso, é isso que eu quero: eles participarem, interagirem na aula.

Por fim, em relação ao terceiro discurso normativo, é possível igualmente, perceber que a defesa por parte dessas professoras da importância de rompermos com a lógica disciplinar não significa necessariamente uma perda de consistência teórica. Se o entendimento hegemônico, no seio da comunidade disciplinar de História, de que o fim dos Estudos Sociais - ao reafirmar a potência da associação entre especialistas e criticidade em um determinado campo disciplinar - significou uma vitória política do movimento de redemocratização no campo educacional, ele contribuiu igualmente para o apagamento, nos debates da área, da singularidade do ensino de História nos Anos Iniciais. As narrativas das professoras nos instigam a problematizar como vem sendo trabalhado os significantes 'tempo' e 'espaço' no ensino de história na educação básica como um todo. Embora essas categorias sejam frequentemente mobilizadas, a interface tempo-espaço, entendida como elementos indissociáveis na produção do social, ainda não recebeu, no campo da historiografia escolar, um olhar atento sobre os seus possíveis efeitos político-pedagógicos no ensino/aprendizagem desta disciplina. Essas breves considerações são suficientes para sustentar a pertinência de explorar outras saídas teóricas para pensar a interface espaço-tempo de forma a garantir as especificidades de cada um desses termos e simultaneamente a potencialidade heurística resultante da hibridização dos mesmos para a leitura do social/político. 


\section{NOTAS IN(CONCLUSIUAS)}

“Querem que a gente ensine a teoria do criacionismo! Hoje o desafio é fazer com que os alunos se interessem por essa questão de tempo e espaço priorizando o respeito às diversas sociedades." (Professora dos Anos Iniciais da educação básica) (informação verbal).

Em tempos em que as políticas educacionais tendem a reativar sentidos de docência pautados na racionalidade técnica que hierarquiza o conhecimento, desvaloriza o/a professor/a, o transformando em mero 'reprodutor' e/ou 'transmissor' do saber hegemonicamente constituído e fixado em propostas curriculares 'miraculosas', bem como alimentam um anticientificismo voluntário, tal como expresso na indignação da professora autora do fragmento narrativo trazido como epígrafe, este texto assume uma posição insurgente e propositiva.

Esse exercício teórico-empírico permitiu justificar a pertinência de explorar outros caminhos investigativos. Procuramos esboçar, alguns argumentos teóricos que ajudem a sustentar a importância do enfrentamento com a 'relação com o saber' para provocar outros sentidos de docência em um contexto de ordem social fissurada. Esse enfrentamento permite fazer emergir no trabalho docente a função discursiva do antagonismo, pela qual é "reativada a lembrança da contingência, do espectro que tudo pode ser diferente." (RETAM0ZO, 2009, p. 114).

Operamos, nessa análise preliminar, com a compreensão do saber da experiência do/a professor/a como espaço de exploração metodológica das possibilidades de articulação entre o currículo de História e a agência docente nos anos iniciais da Educação Básica. Isso significa nem 'falar por', tampouco 'dar o direito' de fala aos subalternos, mas sim investir no trabalho contra a subalternidade. Apostamos que esse seja um caminho reflexivo com possibilidades mais democráticas para pensar o currículo e o exercício da docência que merece continuar a ser explorado pelos/as pesquisadores/as da área.

\section{REFERÊNCIAS}

AIRFUCH, L. 0 espaço biográfico. Dilemas da subjetividade contemporânea. Rio de Janeiro: EdUERJ, 2010.

BIESTA, G. Para além da aprendizagem. Educação democrática para um futuro humano. Belo Horizonte: Editora Autêntica, 2013.

BITTENCOURT, C. (org.). 0 saber histórico na sala de aula. São Paulo: Contexto, 2004.

BUTLER, J. Regulações de Gênero. Cadernos Pagu, n. 42, p. 249-274, jan./jun. 2014.

CHARLOT, B. Da relação com o saber - Elementos para uma teoria. Porto Alegre: Artmed, 2000. 
CHERVEL, A. História das disciplinas escolares: reflexões sobre um campo de pesquisa, Teoria \& Educação, v. 2, p. 177-229, 1990.

CUNHA, E.; LOPES, A. C. Base Nacional Comum Curricular: regularidade na dispersão. Investigación Cualitativa, v. 2, p. 23-35, 2017.

DELORY-MOMBERGER, C. A condição biográfica. Ensaios sobre a narrativa se si na modernidade avançada. Coleção Pesquisa (Auto)Pesquisa autobiográfica e Educação. Natal: EDUFRN, 2010.

DIAS, B. N. de S. Tornar-se professor: sentidos negociados de docência no currículo de Pedagogia da UFRJ. 2018. Dissertação (Mestrado em Educação) - Universidade Federal do Rio de Janeiro, Rio de Janeiro, 2018.

GABRIEL, C. T.; COSTA, W. da. Currículo de História, políticas de diferença e hegemonia: diálogos possíveis. Educação e Realidade, v. 36, n. 1, p. 127-146, jan./abr. 2011.

GABRIEL, C. T. Cultura histórica nas tramas da didatização da cultura escolar ou Por uma outra definição de Didática da História). In: ROCHA, H.; MAGALHÃES, M.; GONTIJO, R. 0 ensino de História em questão: cultura histórica, usos do passado. 1. ed. Rio de Janeiro: FGV, 2015. v. 1, p. 161-182.

GABRIEL, C. T.; FERREIRA, M. S. Disciplina escolar e conhecimento escolar: conceitos sob rasura no debate curricular contemporâneo. In: LBÂNNEO, J. C.; ALVES, N. Temas de Pedagogia: diálogos entre didática e currículo. São Paulo: Cortez, 2012.

GABRIEL, C. T. Objetivação e subjetivação nos currículos de licenciaturas: revisitando a categoria saber docente. Revista Brasileira de Educação, v. 23, p. e230071, nov. 2018a. D01: https://dx.doi. org/10.1590/s1413-24782018230071.

GABRIEL, C. T. Relação com o saber: uma proposta de releitura pós-fundacional. In: LOPES, A. C.; OLIVEIRA, A. L. A. R. M. de; OLIVEIRA, G. G. de S. A teoria do discurso na pesquisa em educação. Recife: Editora UFPE, 2018b.

GRAMSCl, A. Quaderni del carcere. Torino: Einaudi, 1975.

HARTOG, F. Tempos do mundo, história, escrita da história. In: GUIMARÃES, M. L. S. Estudos sobre escrita da história. Rio de Janeiro: Editora Sete Letras, 2007. p. 15-28.

HERNANDEZ, D. M. C. El sujeto en la trama: biografía y poder en-clave posfundacional. Revista Mexicana de Investigation Educativa, v. 19, n. 63, p. 1195-1220, out./dez. 2014.

HOWARTH, D. Discourse. Buckinghtam/Philadephia: Opens University Press, 2000.

LACLAU, E.; MOUFFE, C. Hegemonía y estrategia socialista. Hacia una radicalización de la democracia. Buenos Aires: Fondo de Cultura Económica de Argentina, 2004. 
LARROSA, J. Notas sobre a experiência e o saber de experiência. Revista Brasileira de Educação, n. 19, p. 20-29, jan./abr. 2002.

LIMA, T. P. P. de. Entrelaçando Saberes e Práticas: a história ensinada no 5. Ano do Ensino Fundamental. Curitiba: CRV, 2019.

LOPES, A. C. Por um currículo sem fundamentos. Linhas Críticas, v. 21, n. 45, p. 445-466, out. 2017.

MACEDO, E. “A Base é a base." E o currículo, o que é? In: AGUIAR, M. Â. da S.; DOURADO, L. F. (org.). A BNCC na contramão do PNE 2014-2024: avaliação e perspectivas. Recife: ANPAE, 2018. p. 28-33.

MACEDO, E. As demandas conservadoras do movimento escola sem partido e a base nacional curricular comum. Educação \& Sociedade, v. 38, p. 507-524, 2017.

MACEDO, E. Base Nacional Comum para Currículos: direitos de aprendizagem e desenvolvimento para quem? Educação e sociedade, v. 36, n. 133, p. 891-908, 2015.

MACEDO, E. Fazendo a Base virar realidade: competências e o germe da comparação Revista Retratos da Escola, v. 13, n. 25, p. 39-58, jan./maio 2019.

MACEDO, E.; MLLER, J. L. Políticas públicas de currículo: autobiografia e sujeito relacional. Práxis Educativa, v. 13, p. 948-965, 2018.

MACEDO, E;; RANNIERY, T. Políticas públicas de currículo: diferença e a ideia de público. Currículo sem fronteiras, v. 18, p. 739-759, 2018.

MAHMOOD, S. Teoria feminista, agência e sujeito liberatório: algumas reflexões sobre o revivalismo islâmico no Egipto. Etnográfica, Lisboa, v. 10, n. 1, p. 121-158, maio 2006 Disponível em: http://www. scielo.mec.pt/scielo.php?script=sci_arttext\&pid=S0873-65612006000100007\&lng=pt\&nrm=iso. Acesso em: 3 mar. 2020.

MARCHART, 0. El pensamiento político posfundacional: la diferencia política en Nancy, Lefort, Badiou y Laclau. 1. ed. Buenos Aires: Fondo de Cultura Económica, 2009.

MONTEIRO, A. M. F. da C. Professores de História: entre saberes e práticas. Rio de Janeiro: Mauad X, 2007.

NIEWIADOMSKI, C. Recherche biographique et clinique narrative. Entendre et écouter le Sujet contemporain. Toulouse: Editions Erès, 2012.

NUNES, C. M. F. Saberes docentes e formação de professores: um breve panorama da pesquisa brasileira. Educação \& Sociedade, ano XXII, n. 74, p. 27-42, abr. 2001. 
OLIVEIRA, S. R. F. de. 0 ensino de história nas séries iniciais: cruzando fronteiras entre a história e Pedagogia. História \& Ensino, v. 9, p. 259-272, out. 2003.

PUGAS, M. C. de S. Conhecimento e docência no currículo de pedagogia: entre o pedagógico e o disciplinar. 2013. Tese (Doutorado em Educação) - Universidade Federal do Rio de Janeiro, Rio de Janeiro, 2013.

RETAMOZO, B. M. Las demandas sociales y el estudio de los movimientos sociales. Cinta Moebio, n. 35, p. 110-127, set. 2009.

RETAMOZO, B. M. Lo político y la política: los sujetos políticos, conformación y disputa por el orden social. Revista Mexicana de Ciencias Políticas y Sociales, v. 51, n. 206, sep. 2013. D0l: https://dx.doi. org/10.22201/fcpys.2448492xe.2009.206.41034.

RETAMOZO, B. M. Sujetos políticos: teoria y epistemologia. Um diálogo entre la teoria del discurso, el (re) constructivismo y la filosofia de la liberacíon en perspectiva latinoamericana. Ciencia ergo sum, Toluca: Universidade Autónoma del Estado de Mexico, v. 18, n. 1, p. 81-89, 2011.

SCOTT, J. W. Experiência. In: SILVA, A. L. da; LAGO, M. C. de S.; RAMOS, T. R. O. Falas de Gênero. Tradução: Ana Cecilia Adoli Lima. Santa Catarina: Editora Mulheres, 1999. p. 21-55.

TARDIF, M.; LESSARD, C.; LAHAYE, L. Os professores face ao saber: esboço de uma problemática do saber docente. Teoria \& Educação, n. 4, p. 133-215, 1991.

TARDIF, M. Saberes Docentes e formação profissional. Rio de Janeiro: Vozes, 2002.

VELASCO, D. B. “Realidade do Aluno”, “Cidadão Crítico”, “Conhecimento Escolar”: Que articulações possíveis no Currículo de História? 2013. Dissertação (Mestrado em Educação) - Universidade Federal do Rio de Janeiro, Rio de Janeiro, 2013.

Endereço para correspondência: Avenida Pasteur, 250, Fundos, Praia Vermelha, Rio de Janeiro, Rio de Janeiro, Brasil; carmenteresagabriel@gmail.com 


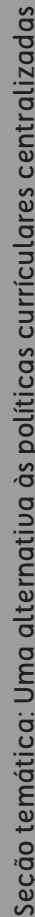

